\title{
EXISTING KNOWLEDGE, KNOWLEDGE CREATION CAPABILITY, AND THE RATE OF NEW PRODUCT INTRODUCTION IN HIGH-TECHNOLOGY FIRMS
}

\author{
KEN G. SMITH \\ University of Maryland, College Park \\ CHRISTOPHER J. COLLINS \\ Cornell University \\ KEVIN D. CLARK \\ Villanova University
}

\begin{abstract}
A field study of top management teams and knowledge workers from 72 technology firms demonstrated that the rate of new product and service introduction was a function of organization members' ability to combine and exchange knowledge. We tested the following as bases of that ability: the existing knowledge of employees (their education levels and functional heterogeneity), knowledge from member ego networks (number of direct contacts and strength of ties), and organizational climates for risk taking and teamwork.
\end{abstract}

The introduction of new products and services is a critical determinant of organizational performance and survival (Damanpour, 1991). By introducing new products and services, organizations can establish new markets and technologies (Burgelman, 1991) and adapt and change to meet new market demands (Brown \& Eisenhardt, 1995). A key premise in the literature on new product innovation is that the rate of new product introduction is a function of a firm's ability to manage, maintain, and create knowledge (Cohen \& Levinthal, 1990; Drazin \& Rao, 2002).

Hargadon and Fanelli (2002) divided the research on knowledge into two streams or approaches. First, there are those studies that center on how knowledge is distributed among a firm's employees, technologies, resources, routines, and procedures. The emphasis of this effort has been somewhat static, focusing on how existing knowledge can be replicated and exploited to affect certain outcomes, such as financial performance (Levitt \& March, 1988). The second stream has been more dynamic, emphasizing how knowledge, and especially new knowledge, leads to the generation of novel organizational outcomes, such as new products (Kogut \& Zander, 1992).

We thank Ming-Jer Chen, Ed Locke, Patrick Maggitti, Mike Pfarrer, Cindy Stevens, Wenpin Tsai, three anonymous reviewers, and Donald Bergh for helpful comments on drafts of our manuscript and Dean Howard Frank and the Robert H. Smith School of Business for financial support for this study.
There is an important symbiosis between these two knowledge streams. For example, it takes some level of existing knowledge or know-how to develop new knowledge, and this new knowledge must at some point lead to new products or services to provide value (Boland \& Tenkasi, 1995; Hargadon \& Fanelli, 2002). Thus, existing knowledge influences the extents to which new knowledge is created, and the new knowledge that is formed is converted to existing knowledge in the form of new products and services. The present research examined the relationship between existing knowledge in an organization and both the organization's knowledge creation capability and how this capability influences the introduction of new products and services. We pursued two research questions: (1) How does the existing or accessible knowledge of a firm impact the knowledge creation capability of the firm? (2) With existing knowledge taken into account, how does the firm's knowledge creation capability affect its level of innovation? To investigate existing or available knowledge in a firm, we focused on the stock of knowledge held by the members of its top management team (TMT) and key knowledge workers and the distribution of knowledge among these firm members; the information and knowledge that are accessible to the TMT and knowledge workers' through their "ego networks"; and the guidance provided through the organization's "climate." Examining knowledge creation capability, we emphasized the firm members' ability to combine and exchange information to obtain new knowledge (Nahapiet \& Ghoshal, 
1998). We studied innovation by examining levels of new products and services firms introduced to the market in 72 high-technology companies. TMT members included key officers and executives who were part of their CEOs' decision-making teams, and knowledge workers included employees who were critical to creating new knowledge or developing innovations within their organizations (Boland \& Tenkasi, 1995). Our unit of analysis in this research was the organization.

\section{THEORY AND HYPOTHESES}

The concept of organizational knowledge is fuzzy and has been defined in a number of ways (cf. Huber, 1991; Nonaka \& Takeuchi, 1995). Following Nonaka and Takeuchi, we defined organizational knowledge as the validated understanding and beliefs in a firm about the relationship between the firm and its environment. In this definition, organizational knowledge is static, reflecting current viewpoints on how existing resources should be configured and exploited for advantage. Further, we assumed that organizational knowledge is composed of two types: explicit knowledge, defined as codified and easily translated facts and information; and tacit knowledge, defined as personal know-how that may be hard to confirm and convey (Nonaka \& Takeuchi, 1995; Polanyi, 1975).

While this static view of knowledge is important, researchers have also taken a more dynamic perspective on knowledge, emphasizing that the creation of new knowledge is essential for the success and survival of firms competing in dynamic environments (Kogut \& Zander, 1992; Nonaka \& Takeuchi, 1995). This literature suggests that organizational knowledge creation is dependent on the ability of organization members to exchange and combine existing information, knowledge, and ideas (Kogut \& Zander, 1992, 1996). Following Nahapiet and Ghoshal (1998), we defined and measured an organization's knowledge creation capability as the extent to which TMTs and knowledge workers have access to one another and other stakeholders, are capable of combining information and knowledge into new knowledge, and perceive value from the exchange and combination process.

Implicit in the notion of exchange is the assumption that individuals hold different levels and types of knowledge and information, and that they can/ will engage in teamwork and communication to learn from one another even when payoffs are uncertain. Combination refers to the process of bringing together "elements previously unconnected or by developing new ways of combining elements previously associated" (Nahapiet \& Ghoshal, 1998:
248). When individuals who hold different levels and kinds of knowledge begin to combine ideas, they create new potential knowledge. When this new potential knowledge is validated, for example by test marketing or other experiments, it is converted into new knowledge.

Our review of the knowledge literature suggests at least three categories of organizational resources that impact knowledge creation capability. First are stocks of individual knowledge in an organization, which Hargadon and Fanelli (2002) referred to as latent knowledge. Second are ego networks, or relational contacts, which facilitate knowledge flows between employees and stakeholders by creating access and motivation to exchange ideas and information (Hargadon \& Fanelli, 2002; Nahapiet \& Ghoshal, 1998). Finally, there are the organizational routines and processes that comprise a firm's climate that informally, and perhaps tacitly, define how the firm is to develop and use knowledge. We theorize that a firm's stocks of TMT and knowledge worker knowledge, ego networks, and organizational climate affect knowledge creation capability, which in turn will affect the creation of new products and services.

\section{Knowledge Stocks and Knowledge Creation Capability}

Most studies of organizational learning recognize employees as a primary repository of organizational knowledge (Argote, 1999). Indeed, the natural abilities, intelligence, and skills of key employees acquired from formal education and job experience constitute the level of an organization's human capital (Becker, 1964). For the purposes of this research, we defined a stock of organizational knowledge as the years of industry experience and education of a firm's TMT members and knowledge workers and as the diversity of the information and knowledge this group holds (as reflected in their functional backgrounds). We considered experience, education, and knowledge diversity a "stock" because they represent the amount of knowledge in a firm at a certain point in time (Dierickx \& Cool, 1989).

Experience. New product knowledge resides in the minds of the managers and knowledge workers responsible for such innovations as new products (Drazin \& Rao, 2002). The knowledge these workers hold is often tacit and noncodifiable (Glaser, 1984), developing and expanding as they spend more time in specific jobs and industries. Therefore, we argue that organizations with TMTs and knowledge workers who have extensive work experience in an industry will have greater expertise and thus more relevant knowledge to bring to the exchange and 
combination process. Further, researchers have distinguished between the knowledge and the knowledge-processing capabilities of experts and novices. Experts have larger knowledge bases, developed through their experiences in specific job domains, a better understanding of how to apply their knowledge, and knowledge structures that are larger and more accessible than those of novices (Glaser, 1984; Lord \& Maher, 1990). Bearing out these notions, empirical research has shown that, compared to novices, experts have richer and more detailed schemata to use in decision making, greater relevant knowledge to recall, an ability to focus more on inconsistencies in information, and less bias in their recall of information (Fiske, Kinder, \& Larter, 1983; McKeithan, Reitman, Rueter, Hirtle, 1981).

Similarly, Hambrick and Mason (1984) argued that key organization members carry their job-related experiences as part of their cognitive makeups and can draw upon this experience in decision making. They noted that organizations run by executives with limited experience will have "restricted knowledge bases" upon which to draw. Cohen and Levinthal (1990) specifically described how a lack of investment in individual knowledge and expertise could bar the development of new knowledge. In view of these arguments, we predict:

Hypothesis 1a. The number of years of experience of a firm's TMT and knowledge workers in a firm is positively associated with the firm's knowledge creation capability.

Education. As with work experience, developmental psychologists support the connection between education level and improved knowledge structures and information processing. In particular, Glaser (1984) argued that changes in knowledge base through education could produce sophisticated changes in cognitive performance. Education helps individuals improve their understanding of what they know, more accurately predict outcomes, better manage time and resources, and monitor results. In effect, education provides new explicit information and knowledge that greatly influence an individual's cognitive reasoning skills.

Hambrick and Mason (1984) similarly argued that workers' formal educations mirror their knowledge bases and cognitive abilities. Bantel and Jackson (1989) argued that better-educated TMTs would have stronger cognitive abilities and as a result generate more novel and creative organizational outcomes. Similarly, the findings of Kimberly and Evanisko (1981) suggested that greater education led to greater innovation by improving cognitive processing and problem-solving ability.
Finally, employees with greater levels of education are likely to be more receptive to new ideas and change (Boeker, 1997). Thus, we predict:

Hypothesis $1 b$. The number of years of education of a firm's TMT and knowledge workers is positively associated with the firm's knowledge creation capability.

Functional heterogeneity. Although level of organizational knowledge, expressed in experience and education, will likely impact what is brought to the combination and exchange process, the variety of types and levels of knowledge organization members hold may also be important (Kimberly \& Evanisko, 1981). Essentially, when individuals within a group hold different information, cognitive conflict is likely to increase, which can lead to more productive exchanges and greater attempts to combine information and knowledge in an effort to reduce conflict (Nemeth, 1992). Cohen and Levinthal (1990) argued that the greater the unique knowledge held by individuals in a firm, the greater the potential for new knowledge to be generated by knowledge exchange. Conversely, when all individuals in an organization hold the same stock of knowledge, creativity may be dampened because members will be less likely to perceive value in the exchange and combination process (Amabile, 1996). We hypothesize that greater diversity in the stocks of knowledge held by a firm's TMT and knowledge workers will yield greater variety in the information brought to the exchange and combination process. This view is consistent with the TMT literature, which suggests that greater diversity in a TMT will lead to a wider range of strategic options and greater creativity in decision making (Boeker, 1997).

Hypothesis 1c. The level of functional heterogeneity of a firm's TMT and knowledge workers is positively associated with the firm's knowledge creation capability.

\section{Ego Networks and Knowledge Creation Capability}

Knowledge creation often depends on the communication within a firm's community of experts (Boland \& Tenkasi, 1995). It follows then that how key employees are connected to one another and to important stakeholders in social relations or networks will be an important indicator of the knowledge they can draw upon in the exchange and combination process (Nahapiet \& Ghoshal, 1998). Hansen (2002) argued that network relations are important to knowledge creation because they in- 
form network members about the existence, location, and significance of knowledge contained in a network and provide an important conduit for the flow of knowledge. We studied the ego-centered networks of TMT members and knowledge workers. Each network consisted of a focal manager or knowledge worker and a set of "category alters" connected to the focal person (Wasserman \& Faust, 1994). ${ }^{1}$ Specifically, we examined the TMT members' and knowledge workers': (1) numbers of direct contacts, (2) ranges of different contacts, and (3) strength of ties. We examined the contacts of each TMT member and knowledge worker in relation to a predefined and bounded set of stakeholders. Our focus was on the relationship of each ego (a top manager or knowledge worker) to a set of alters that were potential sources of knowledge and information from outside their TMT or set of knowledge workers.

Number of direct contacts. One of the most common measures of an individual's set of social relations is the number of people to whom he or she is directly connected (Burt, 1982). Knowledge benefits from having a large number of direct contacts include unique information, more information, and faster information (Burt, 1992). Thus, compared to TMT members and knowledge workers with few direct contacts, those with many direct contacts will be able to obtain information faster, access richer sets of data, and draw from broader sets of referrals, all of which should facilitate knowledge combination and exchange (Nahapiet \& Ghoshal, 1998).

Hypothesis 2a. The number of TMTs' and knowledge workers' direct contacts in a firm is positively related to the firm's knowledge creation capability.

Network range. Network range refers to the scope of different types of contacts contained in TMT and knowledge worker networks (Wasserman \& Faust, 1994). The narrower the range of contacts, the more limited the types of information and knowledge one can draw upon. Networks comprising broader ranges of contacts, however, will have more heterogeneous bases of information and knowledge to draw on (Burt 1982). Access to more diverse knowledge may enhance the possibility of combining and exchanging new information and may also increase the likelihood that an organization will gain value from this process.

\footnotetext{
${ }^{1}$ Ego-centered networks are also referred to as "personal networks." These networks are relational but are incomplete since connections from each ego are only measured to some alters (Wasserman \& Faust, 1994).
}

Hypothesis $2 b$. The range of TMTs' and knowledge workers' contacts in a firm is positively related to the firm's knowledge creation capability.

The strength of network ties. The strength of a tie refers to the nature of a relational contact (Granovetter, 1973). Closeness, long duration, and frequent contact are characteristics of strong ties. In this research, we measured the strength of the tie for each relationship in the network. In general, egos (TMT members and knowledge workers) will be more likely to trust those alters with whom they have strong ties. They will be more likely to share knowledge and information with the latter than with those with whom they have weaker ties, where trust is less evident. Although weak ties may provide certain efficiency benefits, especially when the meaning of information is not problematic (Granovetter, 1973) or when networks are used for search activities (Hansen, 1999), strong ties are critical when information is important, uncertain, or ambiguous. Significant evidence suggests that when ties are strong, individuals will be more willing to exchange information and cooperate for mutual benefit (Krackhardt, 1992).

Hypothesis 2c. The strength of ties in the TMTs' and knowledge workers' sets of relations in a firm is positively related to a firm's knowledge creation capability.

\section{Organizational Climate and Knowledge Creation Capability}

The embedded knowledge and procedural information captured in an organization's climate is important because they serve as a strategic expression to the firm's employees and stakeholders of how things are to be done and prioritized (Schneider, 2000). Organizational climate is defined as the collective attitudes and beliefs of employees about the manner in which they perform their daily jobs (Ashkanasy, Wilderom, \& Peterson, 2000). Climate in this sense is an organizational attitude, reflecting embedded strategic values, beliefs, and assumptions about how the organization should function (Schneider, 2000). ${ }^{2}$ Drawing from O'Reilly, Chatman, and Caldwell (1991), we examined two as-

\footnotetext{
${ }^{2}$ Debate in the literature about the relationship between climate and culture is ongoing. We do not contribute to this debate; instead, we take the position that the concepts of climate and culture are similar and that they represent overlapping explanations of the same phenomena (see Ashkanasy et al., 2000).
} 
pects of organizational climate: the extent to which organizations encourage risk taking versus control, and the extent to which organizations emphasize team behaviors versus individual behaviors.

Climate for risk taking. For exchange and combination to occur, organization members must perceive the willingness of the organization to experiment with new ideas and to take risks in both their development and implementation (Nahapiet \& Ghoshal, 1998). A climate that favors risk taking will encourage employees to test and exchange unusual knowledge and ideas. Weick and Westley (1996) proposed that a climate emphasizing rules and controls would push an organization toward order and away from learning and new knowledge creation. In contrast, a climate that stresses risk taking and experimentation will move the organization toward disorder and experimentation that leads to new knowledge creation.

Hypothesis 3a. A climate that stresses risk taking (as opposed to control) is positively related to a firm's knowledge creation capability.

Climate for teamwork. Although a climate for risk taking may be important for new knowledge creation, it is also important that norms of cooperation and teamwork exist in an organization for exchange and combination to occur. Nahapiet and Ghoshal (1998) argued that an atmosphere of cooperation opens access among group members and creates individual motivation to exchange knowledge with group members. For example, Starbuck (1992) described how norms for openness and teamwork in knowledge-intensive firms facilitated disclosure of information and loyalty building. Tushman and O'Reilly (1997) found that a climate of teamwork was key to effective creativity, and Amabile (1988) found that creativity was hurt when an organization's climate was characterized by a lack of cooperation.

Hypothesis 3b. A climate that stresses teamwork (as opposed to individualism) is positively related to a firm's knowledge creation capability.

\section{Knowledge Creation and Levels of New Product and Service Introduction}

A firm's level of innovation has often been defined and measured as the number of new products or services it generates in a given period (Ettlie,
Bridges, \& O’Keefe, 1984). ${ }^{3}$ Previous research on innovation supports the connection between new knowledge creation capability and development of new products and services. For example, Dougherty, Munir, and Subramaniam (2002) argued that innovation is dependent upon creative solutions and accumulation of new knowledge in an organization. Hargadon and Sutton (1997) suggested that knowledge is imperfectly spread across individuals in an organization and that ideas from one group can solve the problems of another if exchanges are made between the groups. They further noted that when these exchanges are made, existing ideas from one group appear new to the other, and vice versa, resulting in potentially new products or services.

Nonaka and Takeuchi (1995) were more precise in detailing how the knowledge creation process leads to new products and services. They argued that through exchange and combination, tacit existing knowledge is transformed into explicit knowledge. Explicit knowledge takes the form of new "metaphors." A metaphor is a way of understanding one image by thinking representatively of another image (Nonaka \& Takeuchi, 1995). Nonaka and Takeuchi described the following: "This creative, cognitive process continues as we think of the similarities among concepts and feel an imbalance, inconsistency, or contradiction in their association, thus often leading to the discovery of new meaning" (1995: 67). Once new ideas and concepts are explicitly developed through the discussion of metaphors, these ideas are converted into actual models and prototypes. The final step requires that these new models or prototypes be tested and validated: hence the potential new knowledge is validated and justified.

Hypothesis 4. The knowledge creation capability of a firm is positively associated with the number of new products or services it introduces.

In summary, we have argued that stocks of existing organizational knowledge in TMTs and knowledge workers, information and knowledge from TMT and knowledge worker ego networks, and organizational climate will influence a firm's knowledge creation capability, and that knowledge creation capability will, in turn, affect the level of new products and services. Accordingly, we expect that the knowledge creation capability is a necessary

\footnotetext{
${ }^{3}$ This definition is distinct from that for an organization's new knowledge creation capability, which involves the process of combination and exchange of information among individuals to generate new firm knowledge.
} 
requirement to the innovation process. In other words, without the creation of new knowledge, there cannot be innovation. We therefore predict:

Hypothesis 5. The knowledge creation capability of a firm fully mediates the relationship between the firm's existing knowledge, ego networks and climate, and number of new products and services.

\section{METHODS}

We examined firms' knowledge creation capability with a field study of high-technology firms. Data were collected from three key sources: (1) detailed questionnaires completed by TMTs and knowledge workers, (2) a structured interview with the CEO of each firm, and (3) archival data from company records. The CEO of a firm identified the TMT members who were part of the CEO's decisionmaking team, and the knowledge workers included those individuals that the CEO identified as being critical to knowledge creation and innovation. ${ }^{4}$

To ensure that the firms in the sample were similar on basic environmental characteristics-especially a reliance on new knowledge-the sample firms conformed to Milkovich's definition of hightechnology firms as those "that emphasize invention and innovation in their business strategy, deploy a significant percentage of their financial resources to R\&D, employ a relatively high percentage of scientists and engineers in their workforce, and compete in worldwide, short-life-cycle product markets' (1987: 80).

Of the 211 technology firms contacted, 85 agreed to participate in the study. Because of missing data on some measures for 13 firms, the final sample size was 72 companies (representing a 34 percent participation rate). Organizations that agreed to participate did not differ from nonparticipants on either total revenue $\left(t_{211}=1.49\right.$, n.s.) or number of employees $\left(t_{211}=1.22\right.$, n.s. $)$. Furthermore, on a limited sample for which data were available (84 of the 126 firms that did not participate), the level of

\footnotetext{
${ }^{4}$ Across the companies in the study, TMT members were corporate officers, including vice presidents of finance, marketing, manufacturing, R\&D, etc. knowledge workerss that were identified fell into the following categories: $23 \%$ were scientists or senior scientists, $43 \%$ were engineers, $11 \%$ were software developers, $10 \%$ were consultants, $8 \%$ were project managers, and $5 \%$ were marketing or sales personnel. TMT members and knowledge workerss were very similar in their background characteristics, except that the knowledge workers had approximately two years less industry experience.
}

R\&D spending was not different from the $R \& D$ spending of those that did respond $\left(t_{169}=1.03\right.$, n.s.).

An interview with the CEO of each participating firm enabled us to gain her or his support for full participation in the study, identify all the members of the firm's top management team and up to 15 knowledge workers, and collect information on the new products and services introduced in the last year as well as other background information on the company. The questionnaires that were distributed to the TMT and knowledge workers were identical in all respects, except that the surveys for knowledge workers included organizational climate items. An average of 3.52 TMT members (a 56 percent internal response rate) and 5.95 knowledge workers (a 58 percent internal response rate) responded from each firm.

\section{Variable Definition and Measurement}

Measures of stocks of knowledge (experience, education and functional heterogeneity) and ego networks (number of contacts, range of contacts, and strength of ties) were drawn from TMT members' and knowledge workers' responses to questionnaires. Measures of climate (for risk taking and individualism) and knowledge creation capability were drawn from the knowledge workers' questionnaires. ${ }^{5}$ Organization-level scores were created for experience, education, number of direct contacts, strength of ties, and organizational climate by averaging individual participant responses. We used average measures instead of additive measures because the respondents were a representative sample of TMT members and knowledge workers.

Knowledge stocks. Stocks of organizational knowledge were measured in terms of the demographic work experience (years in the industry) and formal education (years of post high school education) of each of the TMT members and knowledge workers who responded. We averaged years of industry experience and education for TMT members and knowledge workers across respondents from

\footnotetext{
${ }^{5}$ We conducted a principal axis factor analysis on the aggregated organizational data to test for construct validity and found support for a five-factor model $(59.5 \%$ of variance explained): stocks of knowledge, ego networks, climate for risk taking, climate for individualism, and knowledge creation capability. We found similar support for a five-factor model using confirmatory factor analysis with individual data (analysis not shown: chi-square goodness-of-fit test $=434.55, p<.001, d f=300$, CFI $=$ .87 , GFI $=.90$, RMSEA $=.06$ ). These analyses provide evidence of convergent and discriminant validity.
} 
the same firm to arrive at organizational scores. Functional heterogeneity was measured with Blau's (1977) heterogeneity index: $\left(1-\Sigma_{i} 2\right)$, where $i$ is the proportion of the group in the ith category. A high score on this index indicates variability in functional backgrounds among respondents, or functional heterogeneity; a low score represents greater functional homogeneity.

Ego networks. Measures of ego networks were collected from the surveys of TMT members and knowledge workers. We used an ego-centered method that relied on a respondent-the ego-and a set of alters who potentially had connections to the ego (Wasserman \& Faust, 1994). We identified nine categories of external alters (representatives of financial institutions, suppliers, customers, competitors, alliance partners, government agencies, trade associations, boards of directors, and other) and four categories of internal firm alters (people from operations, marketing/sales, R\&D, and other). These categories were identified from theory, interviews with executives from high-technology firms not in the study, and pretests with executive MBA students.

Number of direct contacts. TMT members and knowledge workers were asked about their relationships with each of the 13 categories of alters. More specifically, each respondent was asked to identify the number of direct contacts that he or she had for each category of alter. The sum of contacts across each of these categories was the total number of contacts for each respondent. The number of contacts was then measured as the average number of TMT and knowledge worker contacts across respondents. ${ }^{6}$ Because the average number of contacts was not normally distributed, we used the natural logarithmic transformation of the average number of contacts in our statistical analyses.

Network range. Since we were interested in an organization's ability to access diverse sets of knowledge, the network range measure was constructed to capture the breadth of knowledge that could be accessed through the aggregated different types of contacts. More specifically, we followed an approach described by Burt and Minor (1983: 178)

\footnotetext{
${ }^{6}$ The restriction of the number of contacts to a limited set of alters meant that we underestimated the total number of contacts of individuals with large networks. However, given our pretest and the wide range of alternate categories of alters, we felt that only less important contacts were likely to be omitted. Thus, we considered our approach a conservative test of the number of contacts.
}

whereby network range is conceptualized as the number of different status groups (categories of alters) accessed by a network. As noted, 13 categories of alters were identified, and we measured network range as the proportion of categories to which an organization had at least one link.

Strength of ties. As noted above, we asked respondents to identify the number of contacts that they had for 13 categories of alters. In a second step they identified the number of contacts within each alter category that were critical to achieving the company's goals. Respondents were asked to list the names of each of these important contacts and then to answer a set of questions that focused on these important relationships. Strength of ties was measured as an index that included the mean of the duration of relationship, frequency of interaction, and emotional intensity of these key contacts. Duration was measured as the average number of months that top managers' and knowledge workers' relationships had existed. Frequency was measured as the average number of times per month the managers and workers made contact with the alters. Emotional intensity was measured as the average response, on a five-point scale, to the question: "How close is your relationship with these contacts on average." The three items were standardized and combined in a linear additive index at the firm level of analysis.

Organizational climate. Measures of climate were collected from the surveys of knowledge workers. We used items from O'Reilly, Chatman, and Caldwell's (1991) instrument to measure the climate dimensions of risk-taking and teamwork. Climate for risk taking was measured with a fiveitem scale. Because the original teamwork factor comprised only two items, we developed a third item to ensure more consistent measurement of the construct. Respondents were asked to assess their agreement $(1=$ "strongly disagree," to $5=$ "strongly agree") with statements about their organization's climate. Both scales showed good reliability (risk taking, $\alpha=.88$; teamwork, $\alpha=.87$ ) and support for aggregation (see Bliese [1998]; risk taking ICC[1] $=.22$, ICC[2] $=.73$; teamwork ICC[1] $=$ .25 , ICC $[2]=.71)$.

Firm-level knowledge creation capability. Measures of knowledge creation capability were provided by the surveys of the knowledge workers. Drawing from the knowledge literature, we argued that for effective exchange and combination to occur, individuals must: (1) have access to people or groups with specialized information (access to parties); (2) be able to absorb and combine information that has been exchanged (combination capability); 
TABLE 1

Correlations, Means, and Standard Deviations ${ }^{\mathrm{a}}$

\begin{tabular}{|c|c|c|c|c|c|c|c|c|c|c|c|c|c|}
\hline Variable & Mean & s.d. & 1 & 2 & 3 & 4 & 5 & 6 & 7 & 8 & 9 & 10 & 11 \\
\hline 1. Knowledge creation capability & 3.58 & 0.45 & & & & & & & & & & & \\
\hline 2. Years of industry experience & 13.28 & 5.18 & .16 & & & & & & & & & & \\
\hline 4. Functional heterogeneity & 0.47 & 0.26 & .02 & .16 & .13 & & & & & & & & \\
\hline 5. Number of contacts & 112.36 & 79.20 & $.26^{*}$ & .10 & .20 & .04 & & & & & & & \\
\hline 6. Network range & 0.74 & 0.19 & .18 & .17 & $.23^{*}$ & $.26^{*}$ & $.31^{*}$ & & & & & & \\
\hline 9. Culture for teamwork & 3.53 & 0.70 & $.48^{* *}$ & $-.10-$ & $-.26^{*}$ & -.11 & .04 & .08 & $-.28^{*}$ & $-.44 * *$ & & & \\
\hline 10. Number of employees & $1,202.30$ & $2,772.00$ & $.25^{* *}$ & .09 & $.34^{* *}$ & -.17 & .14 & .22 & .19 & .22 & -.18 & & \\
\hline 11. $\mathrm{R} \& \mathrm{D} / \mathrm{sales}$ & 10.15 & 7.25 & .20 & -.01 & .12 & .08 & .17 & -.19 & -.09 & $.23^{*}$ & .10 & $-.24^{*}$ & \\
\hline $\begin{array}{l}\text { 12. Number of new products and } \\
\text { services }\end{array}$ & 17.70 & 27.59 & $.47 * *$ & .19 & $.29^{*}$ & .09 & .22 & .05 & $.31 * *$ & $.32^{* *}$ & $-.27^{*}$ & $.46^{* *}$ & $.35^{* *}$ \\
\hline
\end{tabular}

and (3) anticipate value from the exchange and combination process. We developed 15 five-pointscaled questions to measure the extent to which respondents had access, were capable, and anticipated value from the exchange and combination process (contact the first author for the actual items).

A first-order factor analysis with the 15 knowledge creation items showed that 12 items "loaded" on a single factor, while three remaining items weakly cross-loaded on two additional factors (this analysis is also available from the first author). When we removed the cross-loaded items, we found a single factor with an eigenvalue of 5.73. Because there was strong evidence that these scales might actually be a single factor, the 12 items were combined into a single measure of knowledge creation capability for each individual $(\alpha=.87)$. In addition, there was strong support for aggregation $(\mathrm{ICC}[1]=.37, \mathrm{ICC}[2]=.74)$.

Number of new products and services. Our measure was the number of new products or services an organization had introduced in the most recent year. In a meta-analysis of innovation studies, Damanpour (1991) found that this count is a robust measure of innovation over a wide range of research settings. These data were collected during the interviews with the CEOs. This measure was significantly correlated with the average percentages of sales spent on $\mathrm{R} \& \mathrm{D}(r=.35, p<.01)$, the number of personnel assigned to $\mathrm{R} \& \mathrm{D}(r=.44, p<$ $.01)$, and sales growth $(r=.41, p<.01)$.

Control variables. Organizational size and research and development spending were used as control variables. We measured size using a natural logarithmic transformation of a firm's number of full-time employees. R\&D spending was measured as a percentage of total sales. These measures were obtained from company documents.

\section{RESULTS}

Table 1 reports the means, standard deviations, and correlations of all variables. Table 2 reports the results of regression analyses in which a firm's knowledge creation capability and number of new products and services are the dependent variables. Overall, there is partial support for each of the hypotheses. With regard to the stocks of knowledge hypotheses (Hypotheses 1a-1c), we found that years of education was positively related to knowledge creation capability $(\beta=.34, p<.01)$; functional heterogeneity was marginally positively related to it $(\beta=.18, p<.10)$; and experience was unrelated.

With regard to the ego network hypotheses (Hypotheses 2a-2c), we found a positive relationship between the log of the number of direct contacts and firm knowledge creation capability $(\beta=.20$, $p<.05)$. Consistently with Hypothesis 2c, the strength of network ties was positively related $(\beta=$ $.33, p<.01$ ) to knowledge creation capability. Network range was not related to this capability. Both of our measures of organizational climate were positively related to knowledge creation capability, supporting Hypotheses 3a and 3b (climate for risk 
TABLE 2

Results of Regression Analysis Predicting Knowledge Creation Capability and Innovations ${ }^{\text {a }}$

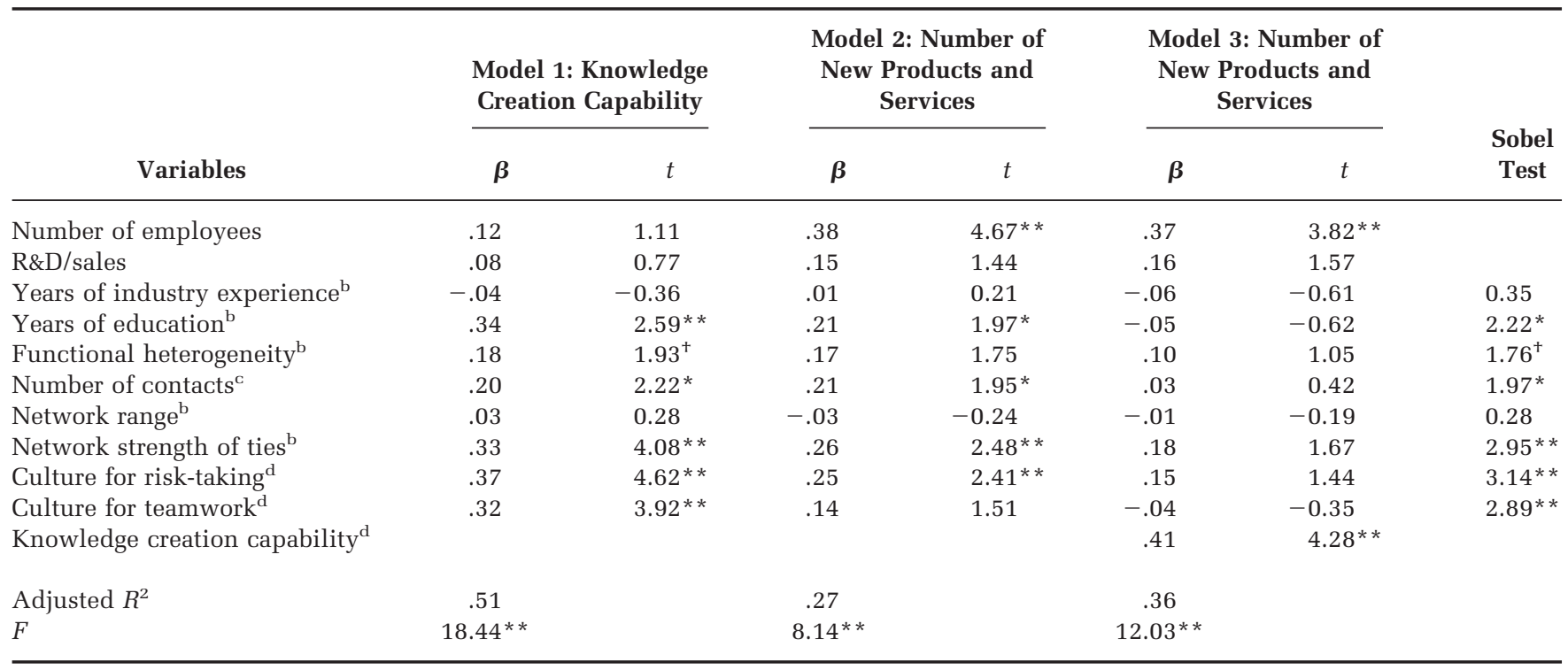

${ }^{\mathrm{a}} n=72$. The dependent variable is the number of new innovations.

${ }^{\mathrm{b}}$ Data were provided by top management team members and core knowledge workers. Results based only on top management team data remained consistent.

${ }^{\mathrm{c}}$ Logarithm.

${ }^{\mathrm{d}}$ Data were provided by core knowledge workers.

${ }^{+} p<.10$

${ }^{*} p<.05$

$* * p<.01$

taking, $\beta=.37, p<.01$; climate for teamwork, $\beta=$ $.32, p<.01){ }^{7}$

Table 2, model 3, also reports regression results with the number of new products and services as the dependent variable. Supporting Hypothesis 4, a firm's knowledge creation capability was positively related to its number of new products and services $(\beta=.41, p<.01)$. Other than organizational size $(\beta=.37, p<.01)$, none of the variables in the model were directly related to the level of innovation.

We also expected that knowledge creation capability would mediate the relationship between the independent variables (stocks of knowledge, ego networks, and organizational climate) and number

\footnotetext{
${ }^{7}$ Because measures of organizational climate and knowledge creation capability were provided from the same source, we performed an additional analysis whereby we randomly selected half of the knowledge workers from each company as sources for climate measures and half of the sample as sources for the firm's knowledge creation capability. In models predicting knowledge creation capability, the beta for risk taking dropped from .37 to .35 (still significant), and the beta for teamwork dropped from .32 to .30 (still significant). This supplemental analysis suggested that common method variance did not account for our organizational climate knowledge creation results.
}

of new products and services. Following Baron and Kenny's (1986) three-step procedure, we first examined the relationships between the independent variables and the dependent variable. As shown in Table 2, model 2, education, number of direct contacts, strength of ties, and climate for risk taking were significantly related to number of new products and services. Second, as demonstrated in Table 2 , model 1, a significant relationship exists between a firm's stocks of knowledge, ego networks, and climate, and our mediator, knowledge creation capability. Third and finally, as model 3 in Table 2 demonstrates, we found that the previously significant relationships between number of new products and services and education, number of contacts, strength of ties, and climate for risk taking were no longer significant when a firm's knowledge creation capability was added to the equation. However, knowledge creation capability remained significantly related to number of new products and services. The findings from this set of analyses suggest that knowledge creation capability fully mediates the relationship between years of education, number of contacts, strength of ties, climate for risk taking, and number of new products and services.

Smaller samples, such as ours, make it difficult 
to find direct relationships between independent variables and more distal dependent variables (Shrout \& Bolger, 2002), as the first step of the Baron and Kenny procedure outlined above demonstrated. Thus, we also tested the significance of the indirect effects of our independent variables on a firm's number of new products and services with a test designed by Sobel (1982; cf. Baron \& Kenny, 1986). The Sobel test is a more direct test of the mediation hypothesis because it examines the combined effects of the path between a dependent variable and a moderator and the path between the moderator and an independent variable (Sobel, 1982). As shown in the final column of Table 3, we found that six of our independent variables had significant or marginally significant indirect effects on number of new products and services through knowledge creation capability. Results of the Sobel test were more robust than those of the Baron and Kenny (1986) procedure, suggesting that knowledge creation capability mediated the relationship between years of education, functional heterogeneity, number of direct contacts, strength of ties, climate for risk taking, climate for teamwork, and number of new products and services.

\section{DISCUSSION}

This research was designed to answer two questions: (1) How does the existing and accessible knowledge in a firm impact the firm's knowledge creation capability and (2) how does the knowledge creation capability affect the level of firm innovation? We found that certain aspects of existing and accessible knowledge did impact a firm's knowledge creation capability, which, in turn, impacted the level of new products and services introduced.

Importantly, the research highlights the relationship between static or existing knowledge in a firm and the more dynamic knowledge creation capability. For example, we showed that stocks of employee knowledge, measured as education level and functional heterogeneity, are related to the process of knowledge creation. From an organizational perspective, hiring and training well-educated employees with varying functional expertise seems to increase the likelihood that such employees will combine and exchange their ideas to form new knowledge. It would be interesting to explore if this exchange and combination occur naturally when knowledge stocks in an organization are high, or whether this process needs to be induced.

Our findings that number of direct contacts and strength of ties were related to firm knowledge creation capability support Nahapiet and Ghoshal's (1998) contention that social networks can be use- ful in the invention of new knowledge. We concur with Hansen (2002) that it would be interesting to examine the nature of the knowledge that is transferred through ego networks and explore the effect that length of network connections has on knowledge sharing. Moreover, one might usefully examine the conditions under which the strength of ties has negative impacts on knowledge creation, for example, when friendship or heightened familiarity between actors gets in the way of their obtaining useful information. In addition, since strong ties are costly and may limit the ability of individuals and organizations to build large networks, in future research, efforts should be made to identify which organizational ties should be strong and where organizations should instead leverage weak ties. We speculate that network range did not show significant coefficients here because there was very little variation in this measure at the firm level.

Our research also suggests that an organization's climate plays a strategic role in knowledge creation capability. We found that a climate that supports risk taking increases that capability. Perhaps employees of such firms are more open to new and novel information and are more likely to interact in new ways, even when the payoff from such activities is not certain. Similarly, firms that cultivate a climate of teamwork are better able to stimulate exchange and combination between employees. Thus, while individualism may have efficiency benefits for organizations, teamwork and collective action seem necessary for knowledge creation.

Finally, we observed that existing and accessible knowledge in a firm affects the rate of new products and services entirely through the firm's knowledge creation capability. This finding suggests that knowledge creation capability may be necessary to successful innovation, and thus may be a key dynamic capability of firms. We treated existing and accessible knowledge as static, measuring "stocks" reflecting current viewpoints and beliefs. On the other hand, knowledge creation capability is dynamic, a process of combination and exchange leading to new knowledge. Organizations' attempts to keep aligned with their environments may require attention to both existing knowledge and the process of knowledge creation.

In conclusion, we examined the relationship between a firm's existing knowledge, its knowledge creation capability, and its new products and service introductions. By empirically linking stocks of knowledge, ego networks, and organizational climates to knowledge creation capability, we provide a more complete picture of how firms create new knowledge and advance the knowledge creation literature. By connecting knowledge creation to 
products/service introductions, we have demonstrated that the study of the knowledge creation capability has promise for increasing understanding of how organizations evolve and adapt to their environments. Finally, by demonstrating that knowledge creation capability mediates the relationship between existing resources and product/service introduction, we show how two somewhat divergent streams in the knowledge literature, one somewhat static and the other dynamic, are related. However, more conceptual and empirical work is necessary if researchers are to fully understand how new knowledge is created and exploited in organizations.

\section{REFERENCES}

Amabile, T. M. 1988. A model of creativity and innovation in organizations. In B. M. Staw \& L. Cummings (Eds.), Research in organizational behavior, vol. 10: 123-167. Greenwich, CT: JAI Press.

Amabile, T. M. 1996. Creativity in context: Update to the social psychology of creativity. Boulder, CO: Westview Press.

Argote, L. 1999. Organizational learning: Creating, retaining and transferring knowledge. Boston: Kluwer Academic.

Ashkanasy, N. M., Wilderom, C. P. M., \& Peterson, M. F. 2000. Introduction. In N. Ashkanasy, C. P. M. Wilderom, \& M. F. Peterson (Eds.), Handbook of organizational culture \& climate: 1 -18. Thousand Oaks, CA: Sage.

Bantel, K. A., \& Jackson, S. E. 1989. Top management and innovations in banking: Does the demography of the team make a difference? Strategic Management Journal, 10: 107-124.

Baron, R., \& Kenny, D. 1986. The moderator-mediator variable distinction in social psychological research: Conceptual, strategic and statistical considerations. Journal of Personality and Social Psychology, 51: 1173-1182.

Becker, G. S. 1964. Human capital. New York: Columbia University Press.

Blau, P. 1977. Inequality and heterogeneity: A primitive theory of social structure. New York: Free Press.

Bliese, P. D. 1998. Group size, ICC values, and grouplevel correlations: A simulation. Organizational Research Methods, 1: 355-373.

Boeker, W. 1997. Executive migration and strategic change: The effect of top manager movement on product market entry. Administrative Science Quarterly, 42: 231-236.

Boland, R. J., \& Tenkasi, R.V. 1995. Perspectives making and perspective taking in communities of knowing. Organization Science, 6: 350-372.
Brown, S., \& Eisenhardt, K. 1995. Product development: Past research, present findings, and future directions. Academy of Management Review, 20: 343-378.

Burgelman, R. 1991. Intraorganizational ecology of strategy making and organizational adaptation: Theory and field research. Organization Science, 2: 239-262.

Burt, R. S. 1982. Toward a structural theory of action. New York: Academic Press.

Burt, R. S. 1992. Structural holes. Cambridge, MA: Harvard University Press.

Burt, R. S., \& Minor, J. 1983. Applied network analysis: A methodological introduction. Thousand Oaks, CA: Sage.

Cohen, W. M., \& Levinthal, D. A. 1990. Absorptive capacity: A new perspective in learning and innovation. Administrative Science Quarterly, 17: 178-184.

Damanpour, F. 1991. Organizational innovation: A metaanalysis of effects of determinants and moderators. Academy of Management Journal, 34: 555-590.

Dierickx, I., \& Cool, K. 1989. Asset accumulation and sustainability of competitive advantage. Management Science, 35: 554-571.

Dougherty, D., Munir, K. \& Subramaniam, M. 2002. Managing technology flows in practice: A grounded theory of sustainable innovation. Academy of Management Proceedings, Technology \& Innovation Management Division: E1-E6.

Drazin, R., \& Rao, H. 2002. Harnessing managerial knowledge to implement product-line extensions: How do mutual fund families allocate portfolio managers to old and new funds? Academy of Management Journal, 45: 609-619.

Ettlie, J., Bridges, W., \& O’Keefe, R. 1984. Organization strategy and structural differences for radical versus incremental innovation. Management Science, 30: 682-695.

Fiske, S., Kinder, D., \& Larter, W. 1983. The novice and the expert: Knowledge based strategies in political cognition. Journal of Experimental Social Psychology, 19: 381-400.

Glaser, R. 1984. Education and thinking. American Psychologist, 39: 93-104.

Granovetter, M. 1973. The strength of weak ties. American Journal of Sociology, 78: 1360-1380.

Hambrick, D., \& Mason, P. 1984. Upper echelons: The organization as a reflection of its top managers. Academy of Management Review, 9: 192-206.

Hansen, M. T. 1999. The search-transfer problem: The role of weak ties in sharing knowledge across organization subunits. Administrative Science Quarterly, 44: 82-111.

Hansen, M. T. 2002. Knowledge networks: Explaining effective knowledge sharing in multiunit companies. Organization Science, 13: 232-248. 
Hargadon, A., \& Fanelli, A. 2002. Action and possibility: Reconciling dual perspectives of knowledge in organizations. Organization Science, 13: 290-302.

Hargadon, A., \& Sutton, R. 1997. Technology brokering and innovation in a product development firm. Administrative Science Quarterly, 42: 716-749.

Huber, G. 1991. Organizational learning: The contributing processes and the literatures. Organization Science, 2: 88-115

Kimberly, J., \& Evanisko, M. 1981. Organizational innovation: The influence of individual, organizational and contextual factors on hospital adoption of technological and administrative innovations. Academy of Management Journal, 24: 689-713.

Kogut, B., \& Zander, U. 1992. Knowledge of the firm, combination capabilities, and the replication of technology. Organization Science, 3: 383-397.

Kogut, B., \& Zander, U. 1996. What firms do? Coordination, identity and learning. Organization Science, 7: 502-518.

Krackhardt, D. 1992. The strength of strong ties: The importance of philos in organizations. In N. Nohria \& R. G. Eccles (Eds.), Networks and organizations: Structure, form, and action: 216-239. Cambridge, MA: Harvard University Press.

Levitt, B., \& March, J. 1988. Organizational learning. In W. R. Scott (Ed.), Annual review of sociology, vol. 14: 319-340. Palo Alto, CA: Annual Reviews.

Lord, R., \& Maher, R. 1990. Alternative information-processing models and their implications for theory, research and practice. Academy of Management Review, 15: 9-28.

McKeithan, K., Reitman, J., Rueter, H., \& Hirtle, S. 1981. Knowledge organization and skill differences in computer programmers. Cognitive Psychology, 13: 307-325.

Milkovich, G. T. 1987. Compensation systems in high tech companies. In C. S. Anderson \& A. Kleingartner (Eds.), Human resource management in high technology firms: 103-114. Lexington, MA: Lexington Books.

Nahapiet, J., \& Ghoshal, S. 1998. Social capital, intellectual capital, and the organizational advantage. Academy of Management Review, 23: 242-266.

Nemeth, C. 1992. Minority dissent as a stimulant to group performance. In S. Worchel, W. Wood, \& J. A. Simpson (Eds.), Group process and productivity: 95-111. Newbury Park, CA: Sage.

Nonaka, I., \& Takeuchi, H. 1995. The knowledge creating company. New York: Oxford University Press.

O’Reilly, C. A., Chatman, J., \& Caldwell, D. F. 1991. People and organizational culture: A profile comparison approach to assessing person-organization fit. Academy of Management Journal, 34: 487-516.

Polanyi, M. 1975. Personal knowledge. In M. Polanyi \&
H. Prosch (Eds.), Meaning: 22-45. Chicago: University of Chicago Press.

Schneider, B. 2000. The psychological life of organizations. In N. Ashkanasy, C. P. M. Wilderom, \& M. F. Peterson (Eds.), Handbook of organizational culture $\&$ climate: xvii-xxi. Thousand Oaks, CA: Sage.

Shrout, P. E., \& Bolger, N. 2002. Mediation in experimental and nonexperimental studies: New procedures and recommendations. Psychological Methods, 7: 422-445.

Sobel, M. E. 1982. Asymptotic confidence intervals for indirect effects in structural equation models. In S. Leinhardt (Ed.), Sociological methodology: 290312. San Francisco: Jossey-Bass.

Starbuck, W. H. 1992. Learning by knowledge-intensive firms. Journal of Management Studies, 29: 713-740.

Tushman, M. L. \& O’Reilly, C. A. 1997. Winning through innovation: A practical guide to leading organizational change and renewal. Boston: Harvard Business School Publishing.

Wasserman, S., \& Faust, K. 1994. Social network analysis. Cambridge, England: Cambridge University Press.

Weick, K., \& Westley, F. 1996. Organizational learning: Affirming an oxymoron. In S. R. Clegg, C. Hardy, \& W. Nord (Eds.), Handbook of organizational design: 440-458. Thousand Oaks, CA: Sage.

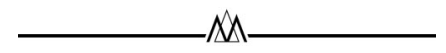

Ken G. Smith (kgsmith@rhsmith.umd.edu) is the Dean's Chaired Professor of Business Strategy in the Robert H. Smith School of Business, University of Maryland. He earned a Ph.D. from the University of Washington. His research interests include competitive dynamics, dynamic capabilities, and strategic decision making.

Christopher J. Collins (cjc53@cornell.edu) is an assistant professor of human resource studies in the College of Industrial and Labor Relations at Cornell University. He received his Ph.D. in organizational behavior and human resources from the Robert H. Smith School of Business at the University of Maryland. His research interests include strategic human resource management, firm innovation and knowledge creation, employee recruitment, and employment brand equity.

Kevin D. Clark (kevin.d.clark@villanova.edu) is an assistant professor of strategic management in the College of Commerce and Finance at Villanova University. He received his Ph.D. in strategic management from the Robert H. Smith School of Business at the University of Maryland. His research has investigated top management team decision making in turbulent environments, the role of top management team social networks in performance, and determinants of innovation and knowledge creation, particularly in technology firms. 
Copyright of Academy of Management Journal is the property of Academy of Management and its content may not be copied or emailed to multiple sites or posted to a listserv without the copyright holder's express written permission. However, users may print, download, or email articles for individual use. 